\title{
Hugo Padeletti (1928-2018)
}

\section{Guillermo Saavedra}

Poeta y periodista cultural

Hay un discurrir secreto de la obra poética de Hugo Padeletti (Alcorta, Santa Fe, 1928-Buenos Aires, 2018) que abarca desde los comienzos de su producción, rubricados con su primer libro, Poemas (1959), hasta 1989, cuando la editorial de la Universidad del Litoral dio a conocer el volumen Poemas 1960-1980 y ese secreto fue, de algún modo, develado. Este último libro, austero y ajeno a todo énfasis como sus propios versos - una tapa blanca que apenas condesciende a anunciar el título en letras negras - trascendió el limitado ámbito de su provincia natal y de la ciudad de Rosario, donde por entonces el poeta y artista visual residía, y convirtió a su autor en una referencia ineludible a la hora de trazar un mapa de la gran poesía de estas tierras. Pero incluso después de eso, y a pesar de que, desde entonces, conoció la fortuna de la publicación frecuente y Padeletti se instaló definitivamente en Buenos Aires, su obra se empeñó en resistirse a la notoriedad.

Más allá del etnocentrismo porteño, que durante décadas pareció agotar todo el crédito concedido a la riquísima poesía del litoral argentino en la justa consideración ofrecida a Carlos Mastronardi y Juanele Ortiz, hay en la propia obra de Padeletti algo irreductible, un gesto y una consistencia que la vuelven, no impopular pero sí sigilosa.

Siempre igual a sí misma desde el punto de vista formal y respecto de los asuntos que reclaman su atención (Padeletti es, en este sentido, autor de una obra única más que de una sucesión de libros), demasiado ceñida a su coreografía de la página como para someterse sin daño a la transmisión oral, enhebrada casi invariablemente por el hilo de una razón elegante y quirúrgica antes que por la emoción, la poesía de Padeletti exige un lector mejor que un oyente, pide intimidad y reflexión, digestión lenta y relectura, para sortear el engaño casi hipnótico de una primera impresión que seduce y persuade de una asimilación inmediata que no es tal.

Asociada a un universo espiritual, el de las filosofías orientales que llevan en su centro la hoy harto manida marca "zen", la obra poética de Padeletti despliega no tanto un conjunto de cuestiones (por otra parte, relativamente limitado) como una actitud que él mismo destaca una y otra vez en su propia obra: la atención. Se trata de una disposición intelectual que hace foco en la cosa de tal modo que esta parece ser la responsable del poema más que un yo lírico que suele brillar por ausencia. El poema no es otra cosa que el registro casi impersonal de una experiencia (sensorial, intelectual, rara vez emotiva). 
Lector caviloso de la gran poesía latina - Propercio, Marcial, Catulo, pero sobre todo Horacio-, que suele aparecer en sus poemas como un rumor de mármoles y bronces, de citas, de tópicos y, a veces, como un lejano eco formal, Padeletti fue también un fervoroso cultor de la poesía española de los siglos de oro, algo que se manifiesta en tonos o humores - la sobriedad de Garcilaso, la causticidad de Quevedo, la erudición sesgada de Góngora, la agudeza de Gracián, la luminosa calma de Fray Luis de León-, pero también en el uso explícito o camuflado de diversos metros, como se verá más adelante. Y cabe mencionar otra cepa especialmente fructífera en la biblioteca implícita que asoma en su obra: la poesía contemporánea en lengua inglesa, en particular la de esa suerte de tríada femenina integrada por Emily Dickinson, Edith Sitwell y, especialmente, Marianne Moore, cuya refinada inteligencia ayuda a Padeletti a configurar una suerte de álgebra de las emociones.

Sobre ese paisaje de lecturas, Padeletti define su propia cartografía, provisto de una brújula que, aunque apunte al pensamiento oriental, nunca pierde su propio norte. Lo que resulta de esas asimilaciones singulares salda cualquier deuda posible con el pasado - Harold Bloom diría que Padeletti encuentra siempre su clinamen, el desvío de la tradición, en el momento justo- e inaugura un espacio nuevo y singular donde se ubica sereno y solitario. Es difícil encontrar huellas de una tradición argentina (acaso Ricardo E. Molinari, pero solo por afinidad de preocupaciones, no por semejanzas formales) en esta obra. Casi podría decirse que es argentina por ausencia, o por microscópicas presencias que volverían estéril cualquier búsqueda en ese sentido.

Hay unos pocos, eficaces procedimientos en la obra de Padeletti, sobre los cuales esta constituye su notable singularidad. El recordado C. E. Feiling y quien esto escribe dieron cuenta de ellas en sendos artículos aparecidos en la revista Babel: la fusión del título con el primer verso del poema, recurso que provoca la sensación de estar dentro del texto aun antes de leerlo; la disposición del texto en la página, suerte de composición o puesta en escena que parece mimar la dirección -lateral, vertical, o sinuosa- del pensamiento; las citas literarias más o menos embozadas; la aparición irregular de rimas internas o finales, asonantes o consonantes; la utilización recurrente de metros clásicos de la poesía en lengua española, en especial el endecasílabo y el heptasílabo.

Quisiera detenerme en este último aspecto. En una inestabilidad solo aparente, sometidos a enmascaramientos, rupturas engañosas, intercalaciones de otros metros (tetrasílabos y pentasílabos), estos dos patrones contribuyen a crear los pulmones rítmicos de una poesía que se pliega o se despliega como una suerte de acordeón métrico y que, por momentos, evoca la serena escansión de las célebres Coplas de Jorge Manrique, otro autor por el que Padeletti sentía una particular admiración. Su constancia en la variación y la simultánea fluidez con que se articulan están dadas por un movimiento que consiste en desfasar violentamente los períodos rítmicos y los sintácticos, a través de fuertes encabalgamientos, proponiendo por lo menos dos lecturas: la que se deja engañar por el ocultamiento de los metros fijos y sigue la sintaxis del poema y la que se dedica a reconstruir esos metros, escandir el ritmo, sospechar la inminencia de la rima. En rigor, estas dos lecturas son simultáneas, coexisten, y sus efectos combinados dan, al fin y al cabo, la auténtica e incomparable respiración del poema padelettiano. Esa respiración, fluctuante, sinuosa, siempre elegante, sostiene y desde ella es perceptible el movimiento intelectual, la emoción y una suerte de nostalgia de la forma desde la cual y hacia la que esta poesía está yendo y viniendo continuamente. En su resonancia entre el metro fijo y el verso libre, en la cita ligeramente modificada, en las rimas aparentemente casuales, la poesía de Padeletti se cumple como reformulación de ciertas tradiciones pero en una dirección que le es propia.

Con estos medios de transporte, cada poema recorre el blanco de la página como una oscilación eléctrica, un relámpago suntuoso que se obstina una y otra vez en 
preguntarse por el sentido de un acontecer. Cada poema proyecta sobre las cosas del mundo una luz distinta e incide sobre una cara diferente de ese poliedro opaco que da en llamarse lo real. Con deliberada actitud selectiva, la misma que caracteriza su delicada y casi aérea obra visual, los poemas de Padeletti se ocupan de algunas cosas, no de todas. Pero cada cosa que ingresa en su poesía - una rosa, una cita, un pensamiento, un inodoro- es sometida a un delicioso igualitarismo ontológico. Ubicados en ese plano, los objetos de su poesía parecen sufrir un proceso de destilación intelectual que los adelgaza, los torna leves, casi espirituales. La paradoja, solo aparente, de Padeletti es que, a pesar de su evidente voluntad estética, su poesía tiende a atribuirle, como quedó dicho, la responsabilidad a los objetos de su atención, no a la conciencia, ni a un yo siempre remiso a ser protagonista. Como si de las cosas de este mundo brotara una verdad o su irreductible misterio. Como si existiera, en fin, la voz de la experiencia. 
